\title{
Electrical resistance measurement for in-situ monitoring of fatigue of carbon fabric composites
}

\section{De Baere, W Van Paepegem and J Degrieck}

Department of Mechanical Construction and Production, Faculty of Engineering, Ghent University. Sint-Pietersnieuwstraat 41, B-9000 Gent, Belgium.

E-mail: Ives.DeBaere@UGent.be

\section{Abstract}

This study investigates whether fatigue damage can be monitored using the electrical resistance of the carbon fabric reinforced thermoplastic. A four-probe method, using rivets for the current injection and conductive tape for the voltage measurement is presented. Quasi-static and hysteresis tests are presented to assess the method, with promising results. Then, fatigue tests at both 2 and $5 \mathrm{~Hz}$ are discussed. For the material under study, neither stiffness reduction nor permanent elongation occurred and therefore, fibre fracture is not the dominant mode of damage. As a result, the electrical resistance measurement was not capable of monitoring damage growth inside the specimen, since it is sensitive to fibre failure.

Keywords: Damage monitoring, carbon fabric reinforced thermoplastic, electrical resistance.

\section{Introduction and Principle}

An ideal solution for monitoring damage in a material is to use the material itself as a sensor. This is possible in the case of carbon fibre-reinforced polymers, since carbon fibres are electrical conductors embedded in an insulating matrix [1].

The principle of electrical resistance measurement is illustrated in Figure 1. Since carbon fibres conduct electricity, they can be represented by resistors and for a carbon fabric, one can imagine the following symbolic lay-out (Figure 1 (a)). The total resistance of the composite is $R_{\text {tot }}$.

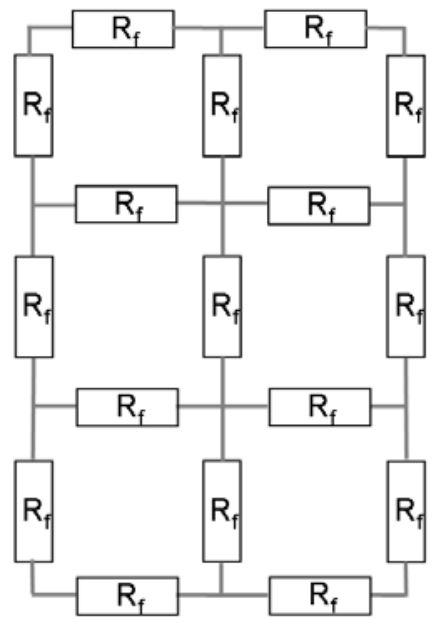

(a) Undamaged composite

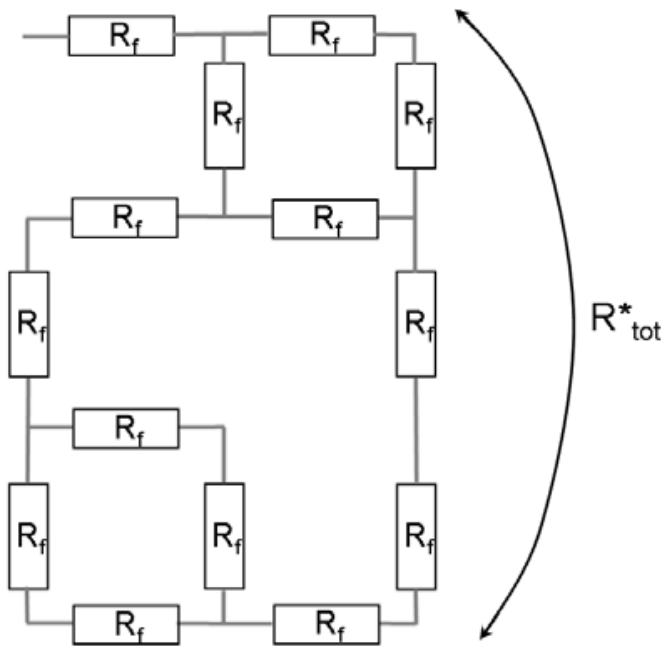

(b) Damaged composite

Figure 1 Electric network of resistors, representing a fabric of carbon fibres in an insulating matrix. 
If a fibre breaks, then the current can no longer travel through that fibre and needs to find another path. This means that the corresponding resistor disappears, leading to a situation as depicted in Figure 1 (b).

The more carbon fibres are broken, the fewer paths are available for the electric current, so the higher the total resistance $\mathrm{R}{ }_{\text {tot }}$ becomes. This ends with fracture of the specimen, giving infinite resistance. This conclusion may also be found in various articles about this subject $[1,2,3,4,5,6,7,8,9,10,11]$.

While doing the literature study, it was noticed that most authors concentrated their work on polymers with unidirectional fibre reinforcement $[4,5,6,7,8,9,10,11,12$, 13]. Occasionally, cross-ply laminates are studied [3, 4, 5, 11, 12], but materials reinforced with fabrics were never closely observed using this technique. A possible reason may be that the sensitivity of resistance measurement tends to decrease if there are more transverse fibre contacts, which is already the case with cross-ply laminates, but will be even more apparent in fabrics. The latter has been proven theoretically by Xia et al. [8]. Nevertheless, we have tried this method to observe damage in the used carbon fabric-reinforced PPS. An advantage of cross-ply laminates is that the potential distribution on the surface of the laminate is much more uniform than with unidirectional samples even when point surface introduction of the current is used, because the transverse current is carried by the off-axis plies [5]. This will be even more so for a fabric-reinforcement.

There have already been a few studies on the use of this technique for monitoring fatigue $[4,5,11,12,13,14]$, but as previously mentioned, the focus lies mostly on unidirectional $[4,5,11,13,14]$ or cross-ply reinforcement $[5,12]$. In [4], a very promising correlation between stiffness degradation and relative resistance change was found, but for a unidirectional carbon fibre reinforced epoxy.

The order of change tends to vary with the used material. In [4], the resistance increased about $30 \%$ for the UD carbon epoxy, whereas in [12], an increase of $5 \%$ was reached at failure for a cross-ply material.

In some industries, for instance in the aeronautical industry, composites are attached using rivets. In [15], the authors have examined whether these rivets can be used for the purpose of electrical resistance measurement for static tests, with good results. This study investigates whether the same principle can be used to monitor a fatigue experiment.

In the next paragraph, the used materials and experimental setups are discussed. This is followed by the discussion of the conducted experiments, both under quasi-static and fatigue loading conditions. Finally, some conclusions are drawn.

\section{Materials}

\subsection{Composite Material}

The material under study was a carbon fabric-reinforced polyphenylene sulphide (PPS), called CETEX. This material is supplied to us by Ten Cate. The fibre type is the carbon fibre $\mathrm{T} 300 \mathrm{~J} 3 \mathrm{~K}$ and the weaving pattern is a 5-harness satin weave with a mass per surface unit of $286 \mathrm{~g} / \mathrm{m}^{2}$. The 5-harness satin weave is a fabric with high strength in both directions and excellent bending properties. 
The carbon PPS plates were hot pressed, only one stacking sequence was used for this study, namely a $\left[\left(0^{\circ}, 90^{\circ}\right)\right]_{4 \mathrm{~s}}$ were $\left(0^{\circ}, 90^{\circ}\right)$ represents one layer of fabric and therefore eight layers in total were laid up.

The in-plane elastic properties of the individual carbon PPS lamina were determined by the dynamic modulus identification method as described in [16] and are listed in Table 1 .

Table 1 In-plane elastic properties of the individual carbon/PPS lamina (dynamic modulus identification method).

\begin{tabular}{llr}
\hline $\mathrm{E}_{11}$ & 56.0 & $\mathrm{GPa}$ \\
$\mathrm{E}_{22}$ & 57.0 & $\mathrm{GPa}$ \\
$\mathrm{v}_{12}$ & 0.033 & - \\
$\mathrm{G}_{12}$ & 4.175 & $\mathrm{GPa}$ \\
\hline
\end{tabular}

The tensile strength properties were determined at the Technical University of Delft and are listed in Table 2 .

Table 2 Tensile strength properties of the individual carbon/PPS lamina (Mechanical testing at TUDelft).

\begin{tabular}{lcl}
\hline $\mathrm{X}_{\mathrm{T}}$ & 717.0 & $\mathrm{MPa}$ \\
$\varepsilon_{11}$ ult & 0.011 & - \\
$\mathrm{Y}_{\mathrm{T}}$ & 754.0 & $\mathrm{MPa}$ \\
$\varepsilon_{22}$ ult & 0.013 & - \\
$\mathrm{S}_{\mathrm{T}}$ & 110.0 & $\mathrm{MPa}$ \\
\hline
\end{tabular}

The test coupons were sawn with a water-cooled diamond saw. The dimensions of the coupons are shown in Figure 2. Electrically isolating end tabs of glass fibre-reinforced Polyethylene Imide (PEI) are bonded to the end of the specimen, but a small zone is left uncovered to mount the electrodes, as described in [15].

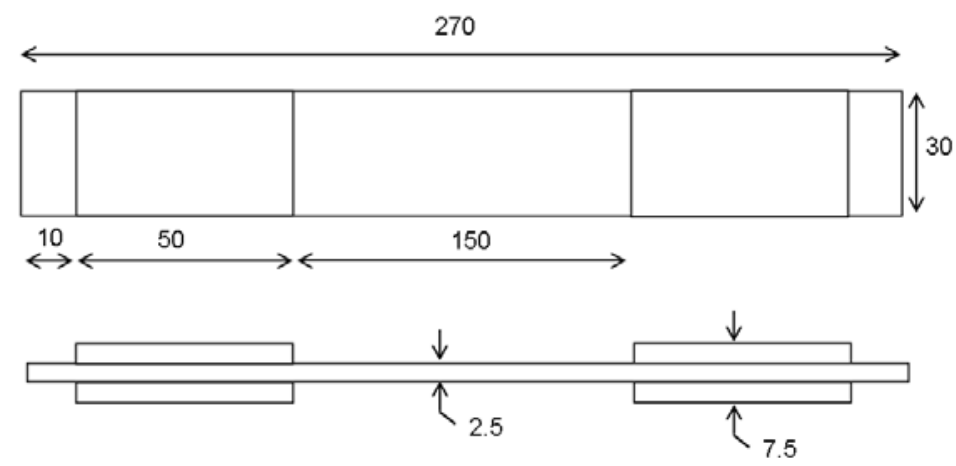

Figure 2 Dimensions of the used tensile coupon, equipped with isolating tabs of $\left[ \pm 45^{\circ}\right]_{5 \mathrm{~s}}$ glass fibre PEI.

\subsection{Equipment}

All tensile tests were performed on a servo-hydraulic INSTRON 8801 tensile testing machine with a FastTrack 8800 digital controller and a load cell of $\pm 100 \mathrm{kN}$. The used power source for the resistance measurement was a PL330-32V-3A PSU from Thurlby Thander instruments (TTi). For the registration of the tensile data, a combination of a National Instruments DAQpad 6052E for fireWire, IEEE 1394 and the SCB-68 pin 
shielded connecter were used. The load, displacement and strain, given by the FastTrack controller, as well as the extra signals from the resistance measurement were sampled on the same time basis.

\section{Method}

The resistance of the specimen is measured by injecting a known current through two electrical contacts on the specimen and measuring the voltage between two electrodes. In [15], a two-probe technique was used, which means that the voltage is measured on the same electrodes where the current is introduced. For these electrodes, rivets were used, as illustrated in Figure 3, which are mounted in the stress free zone of the specimen.

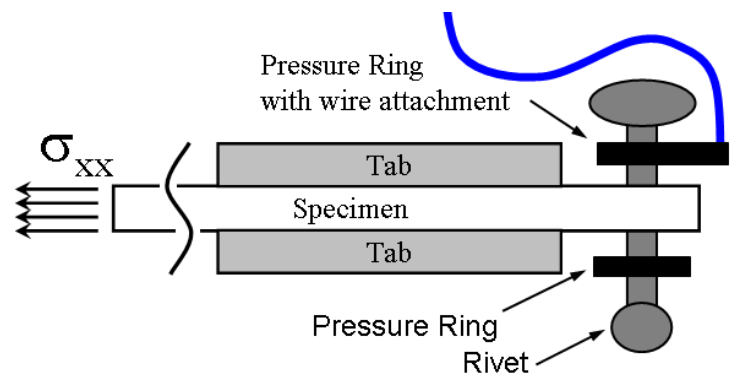

Figure 3 Illustration of how the rivet is mounted in the stress free zone of the specimen.

An example of a specimen can be seen in Figure 4, a detail of the riveting is depicted in Figure 5.

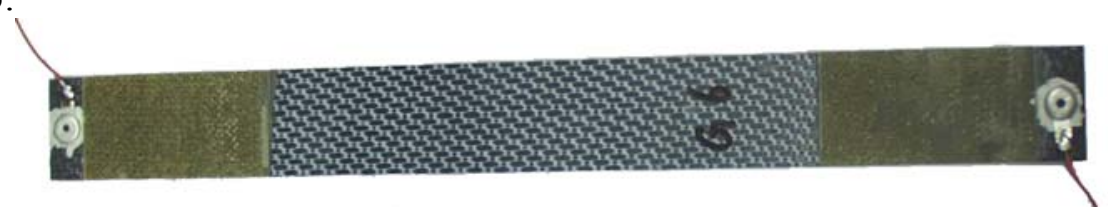

Figure 4 Specimen prepared with rivets for electrical resistance measurement.

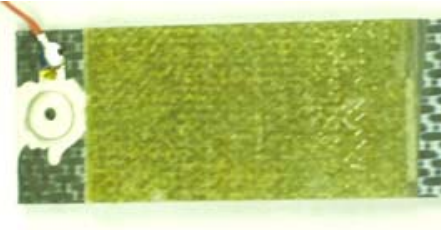

(a) top view

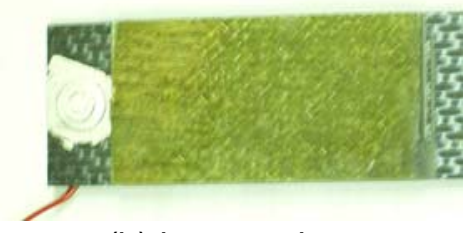

(b) bottom view

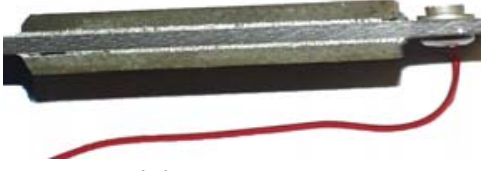

(c) side view

Figure 5 Detailed pictures of the rivet.

This principle worked excellent for the quasi-static tests, but an extra parameter is introduced when conducting fatigue experiments: time. Therefore, the time-stability of this setup was first tested by measuring the resistance of an unloaded specimen for an extended period of time, corresponding with an average fatigue test. Several of these tests have been performed in order to have reproducible results; they are shown in Figure 6. For specimen I7, a current of $1000 \mathrm{~mA}$ was injected and three successive tests (I7-1 till I7-3) were done. After a certain period of time, the current was removed and the specimen was left untouched for a few hours. Afterwards, the current was injected again and the measurement was redone to see if the increase in resistance was reversible. It can clearly be noticed that the resistance change is irreversible, since the initial resistance of I7-2 differs from the starting resistance of I7-1. Also, should this be a reversible phenomenon, one would expect coincident curves for all three tests and this is definitely not the case. The same experiment was done on specimen I8 (I8-1 and I8- 
2), but with a current of $100 \mathrm{~mA}$, to assess whether the high current may cause the increase. Again, there is an irreversible increase in resistance, since the initial value of I8-2 is higher than the initial value of I8-1. To assess whether this effect is due to the data acquisition unit, a reference resistor was also measured using the same setup. It can be noted that the measured value is constant, which rules out the data acquisition unit.

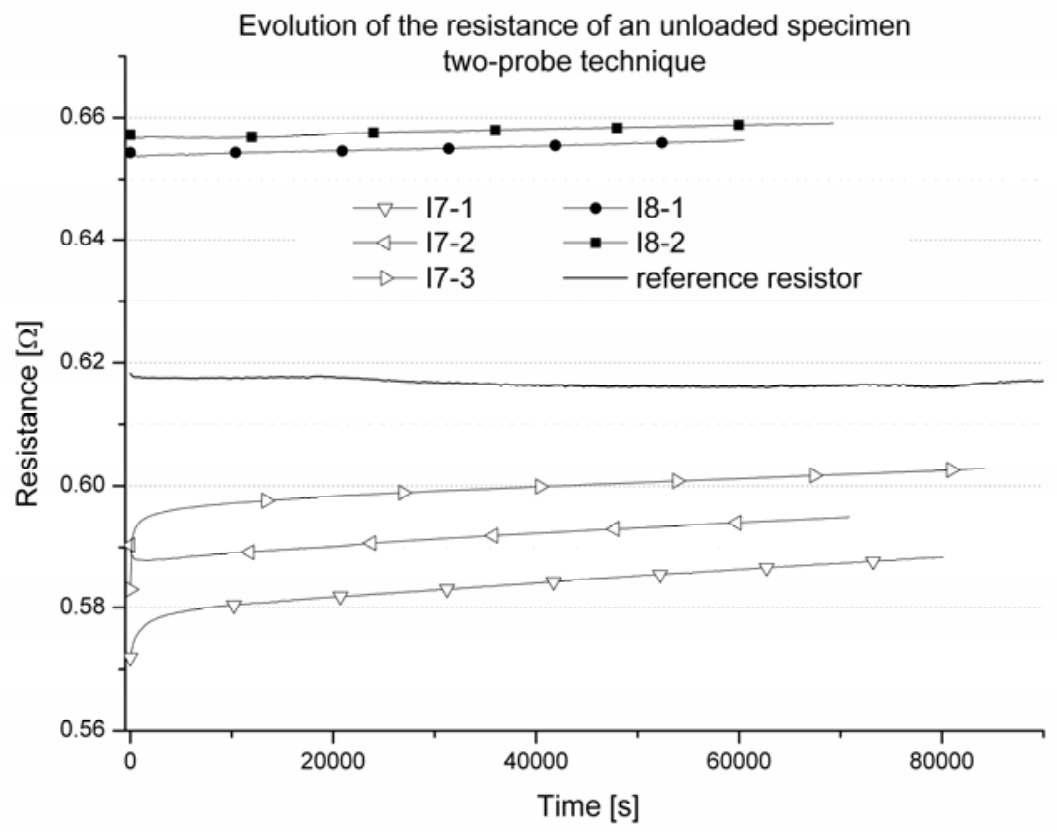

Figure 6 Evolution of the resistance of an unloaded specimen, measured with the two-probe technique.

It must be remarked that during the experiments described above, the temperature was monitored. There was no significant increase or decrease of the temperature (measured difference, both increase and decrease was less than $2^{\circ} \mathrm{C}$ ), which rules out the temperature as possible influence.

For the quasi-static tests, this increase did not have any influence on the measurement, since the total time needed for the experiment was too short for any significant increase to occur. For the fatigue experiments, however, this could be a major problem, since the value of the increase due to fatigue damage may be of the same order as the increase measured above.

The main reason for this increase is that in the two-probe method, the contact resistance of the electrodes is also measured. The principle of the two-probe method is illustrated in Figure 7.

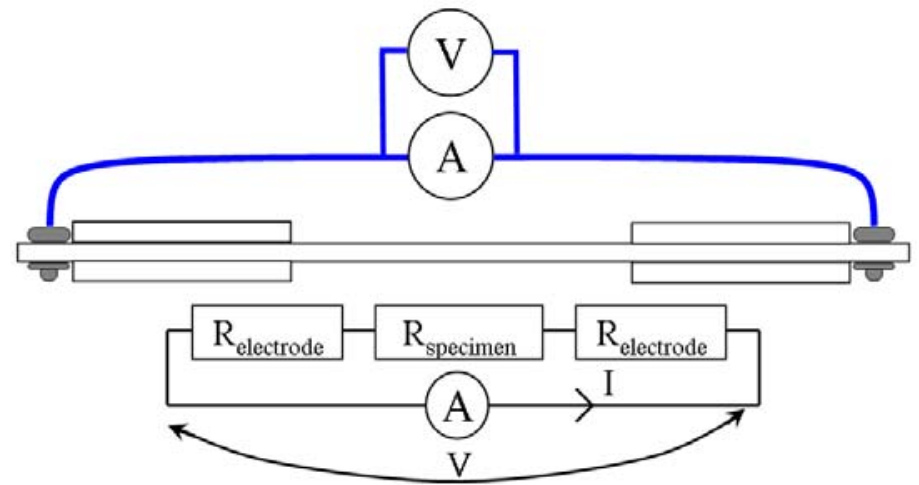

Figure 7 The two-probe system for resistance measurement. 
The voltage measured by the system is given by:

$$
V=R_{\text {tot }} . I=\left(2 R_{\text {electrode }}+R_{\text {specimen }}\right) . I
$$

Therefore, if the resistance of the contact electrodes varies in time, this variation is also measured by the system and this is the reason why the measurements depicted in Figure 6 are not stable. The variation of the contact resistance may have various reasons, such as creep of the composite around the rivets, electrochemical reactions in the soldered connection between rivet and wire ... It is impossible to model all these effects on the total resistance, so the best solution is to avoid measuring the contact resistance.

Therefore, a four-probe method is considered. This setup is also used in $[2,5,7,10,12$, $13,17,18]$. This technique is said to be more accurate [7, 10] than the two-probe technique, but is more complicated as experimental setup. Furthermore, it may not represent sub-surface behaviour if all probes are mounted on the same surface [5]. The used setup for this research is illustrated in Figure 8. The two electrodes for current injection are the same as for the two-probe method, but for the voltage electrodes, rivets are no option since this would require drilling holes in the loaded part of the specimen. Therefore, a special conductive copper tape is wound around the specimen and the wires for the voltage measurement are then attached to this tape. By winding the electrode around the specimen, subsurface behaviour is represented. The area underneath the tape is degreased with acetone, but it is not polished, since this would damage the surface and induce premature fatigue failure.

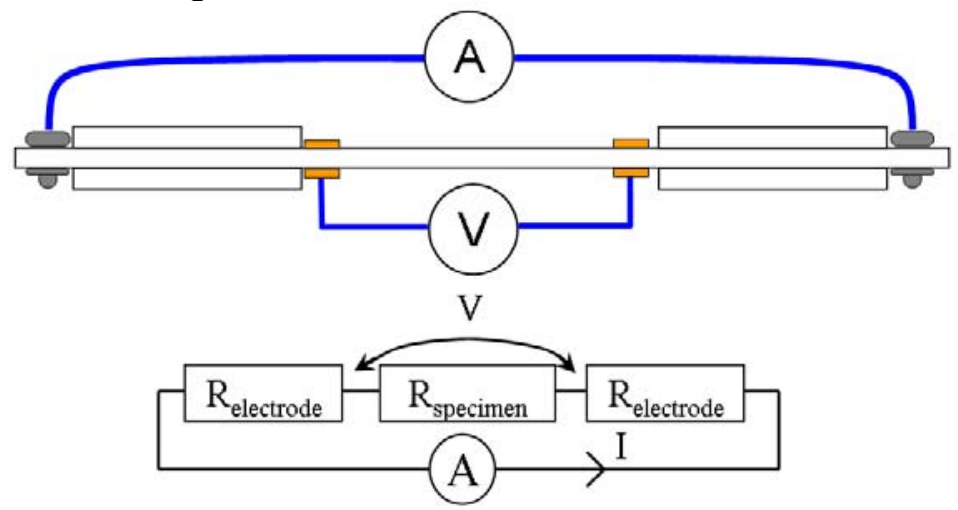

Figure 8 The four-probe system for resistance measurement.

As for the two-probe method, the current still travels through the contact electrodes $\mathrm{R}_{\text {electrode, }}$, but the measured voltage is now given by:

$$
V=R_{\text {specimen }} . I
$$

Normally, the voltage measurement unit has a very high input impedance, so no current travels through the wires from the specimen to the unit and therefore, the contact resistance of the copper conductive tape has no influence. However, some say the quality of the electrodes tends to have a small influence [19].

Of course, the time-stability of this method should still be tested. Again, a current of $1000 \mathrm{~mA}$ was injected through the specimen and the resistance was measured for an extended period of time. The result was also depicted in Figure 9 and as can be seen, no increase occurs. In fact, the signal is even more stable than the reference resistor measurement, which proves that the four-probe method is definitely an improvement. 


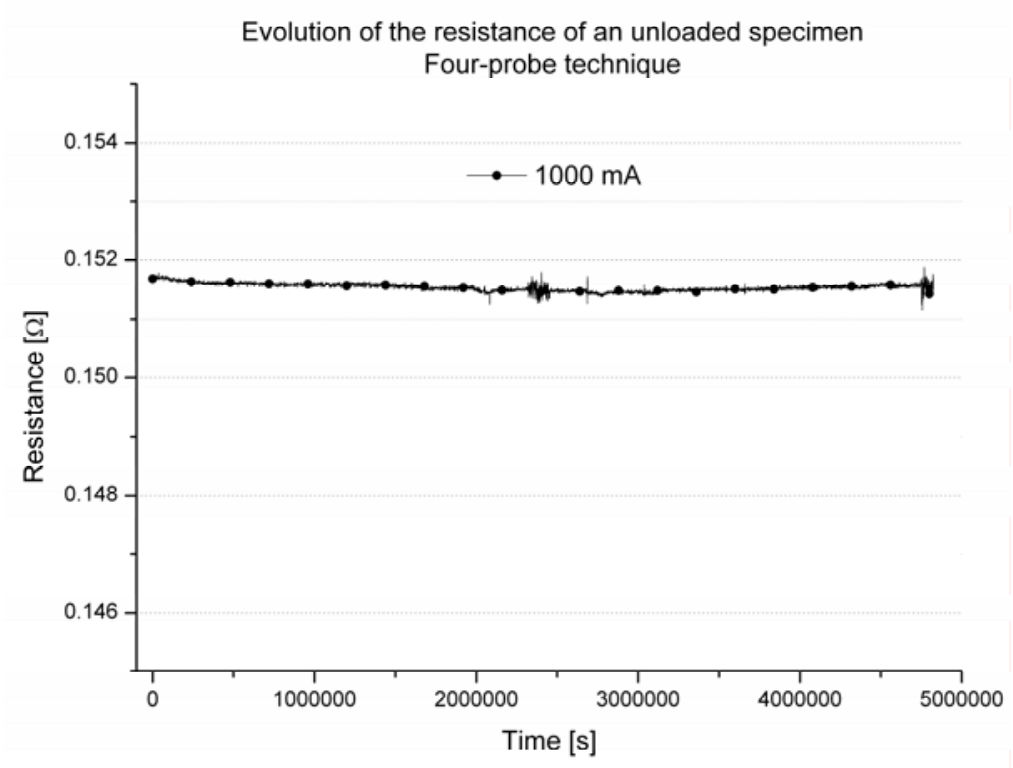

Figure 9 Evolution of the resistance of an unloaded specimen, measured with the four-probe technique.

Furthermore, the low value of the resistance should be noted. The voltage, given by the current source, was about $0.7 \mathrm{~V}$, while the actual resistance of the specimen is only $0.1518 \Omega$, meaning that the contact resistance of each of the rivets is about $0.275 \Omega$. As a result, the sensitivity of the setup should have increased.

The choice of $1000 \mathrm{~mA}$ was made to further increase the signal to noise ratio. Of course, this current could cause heating of the specimen due to Joules heating, but temperature was monitored for all of the experiments and no significant increase in temperature was noted. The increase in current however did have a significant effect on the noise on the signal, as is illustrated in Figure 10. It must be noted that the measured noise is white noise, the average value of both signals is 0 and this noise can be easily filtered away by using a low band pass filter.

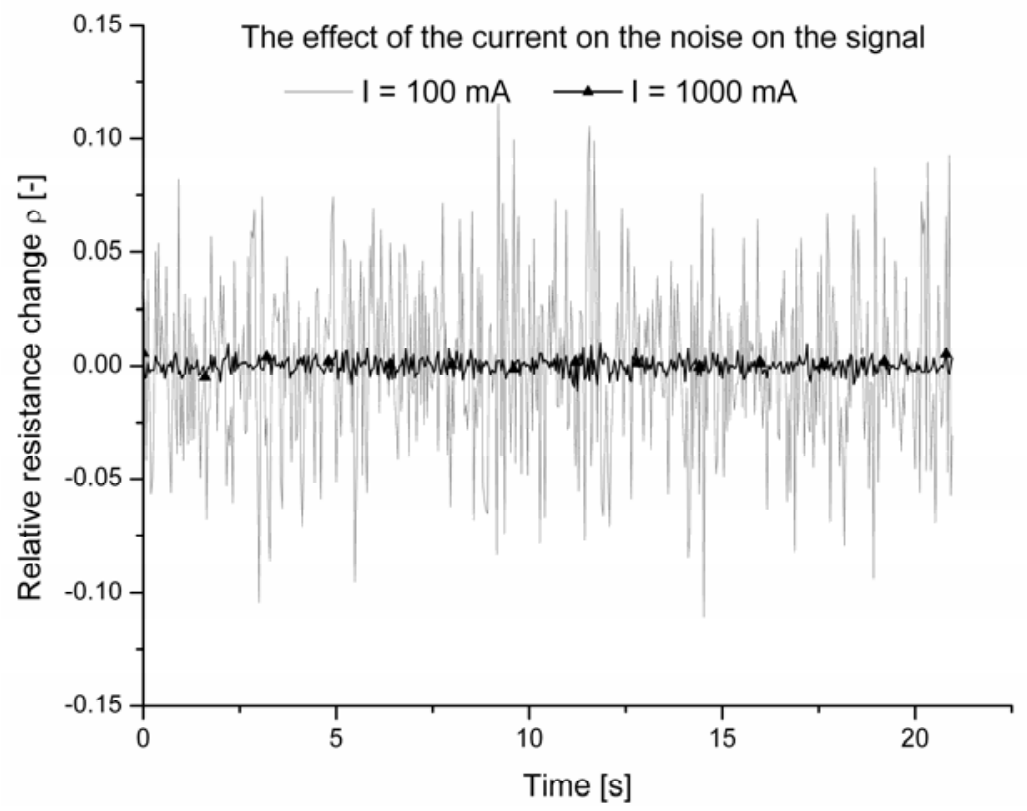

Figure 10 Increasing the current from $100 \mathrm{~mA}$ to $1000 \mathrm{~mA}$ drastically reduces the noise on the signal. 


\section{Experiments and Discussion}

\subsection{Quasi-static tests}

In the previous paragraph, the four-probe method was introduced. Before conducting any fatigue experiments, first the conclusion made in [15] should be verified. Therefore, a few static tests have been performed, of which the results are shown in Figure 11; both the measurement and the filtered signal are presented. The tests were displacement controlled at a speed of $2 \mathrm{~mm} / \mathrm{min}$. The relative resistance change $\rho$, plotted in the graph is calculated as:

$$
\rho=\frac{\Delta R}{R_{0}}=\frac{R_{t}-R_{0}}{R_{0}}
$$

where $R_{0}$ is the resistance of the unloaded specimen and $R_{t}$ is the resistance of the loaded specimen.

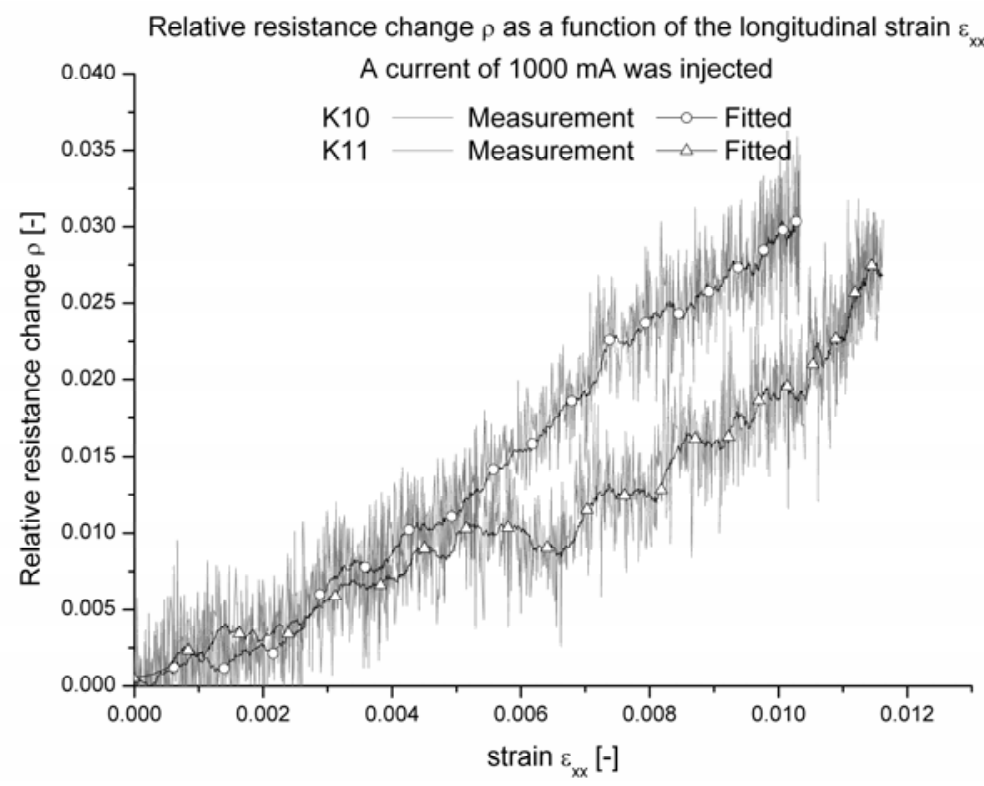

Figure 11 Quasi-static tests of the four-probe method for resistance measurement.

When comparing these static results to the ones in [15], it should be noted that the value of $\rho$ at failure is more than double. Here, values of 0.0304 for K10 and 0.028 for K1 1 are found, compared to values of 0.011 and 0.013 found in [15]. This illustrates the increase in sensitivity of the four-probe over the two-probe method. On the other hand, the higher sensitivity might be the reason why the reproducibility is not as high as in the previous study. The increase of both signals is very similar, apart from the small dip in the curve of K11.

\subsection{Hysteresis tests}

Because of the promising results from the previous paragraph, the next step towards fatigue loading is now taken. A number of hysteresis tests are performed to assess whether the resistance has an irreversible growth. As was shown in $[5,10]$ the resistance should increase if the specimen elongates, but as long as no damage occurs, the resistance should decrease to its original value if the load is removed. Therefore, a number of successive loading cycles were imposed on the specimen, starting from $100 \mathrm{MPa}$ and then increasing with $50 \mathrm{MPa}$ per cycle until fracture occurred. The tests 
were done in displacement controlled mode using a speed of $2 \mathrm{~mm} / \mathrm{min}$. The corresponding stress-strain curves are shown in Figure 12. The different tests are given an offset of 0.0015 along the strain-axis for a clear picture. It must be noticed that no stiffness degradation occurs and that there is only very limited permanent deformation. Premature failure in the tabs occurred for specimens L1 at $600 \mathrm{MPa}(=11$ cycles) and for L5 and L6 at $500 \mathrm{MPa}$ (=9 cycles). The latter is due to bad bonding quality on PPS and the occurring stress combinations underneath the tabs, as explained by the authors in [20]; H14 failed outside the tabs at $753 \mathrm{MPa}$ (=14 cycles).

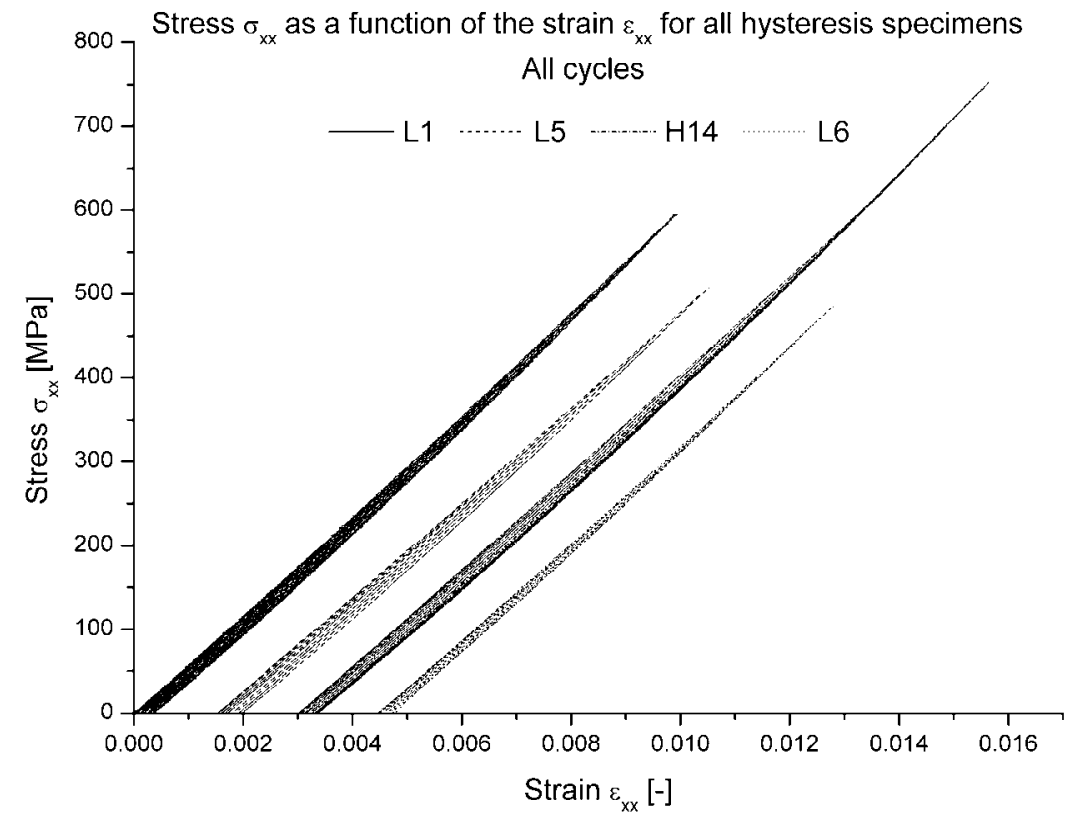

Figure 12 Stress as function of the strain for the hysteresis tests.

The evolution of the relative resistance, as well as the corresponding strain is given in Figure 13 and Figure 14 for specimen L5 and H14 respectively. The tests on specimens L1 and L6 gave a similar image as L5. 


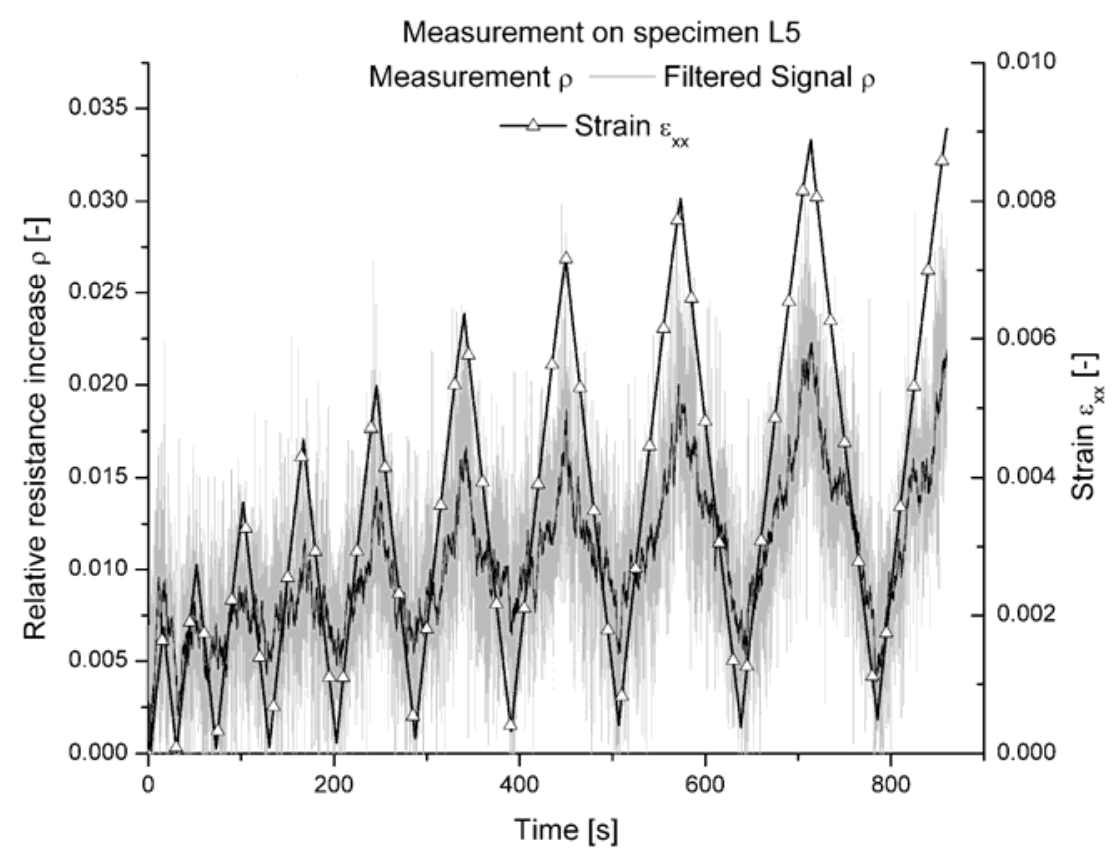

Figure 13 Relative resistance and strain as a function of time for specimen L5.

It must be noted that there is a lot more (white) noise present on the signal L5 than on the static tests. Investigation yielded that a power converter, which generates large electromagnetic fields was working close by. This system was shut down before conducting the test on $\mathrm{H} 14$, resulting in a lot less noise.

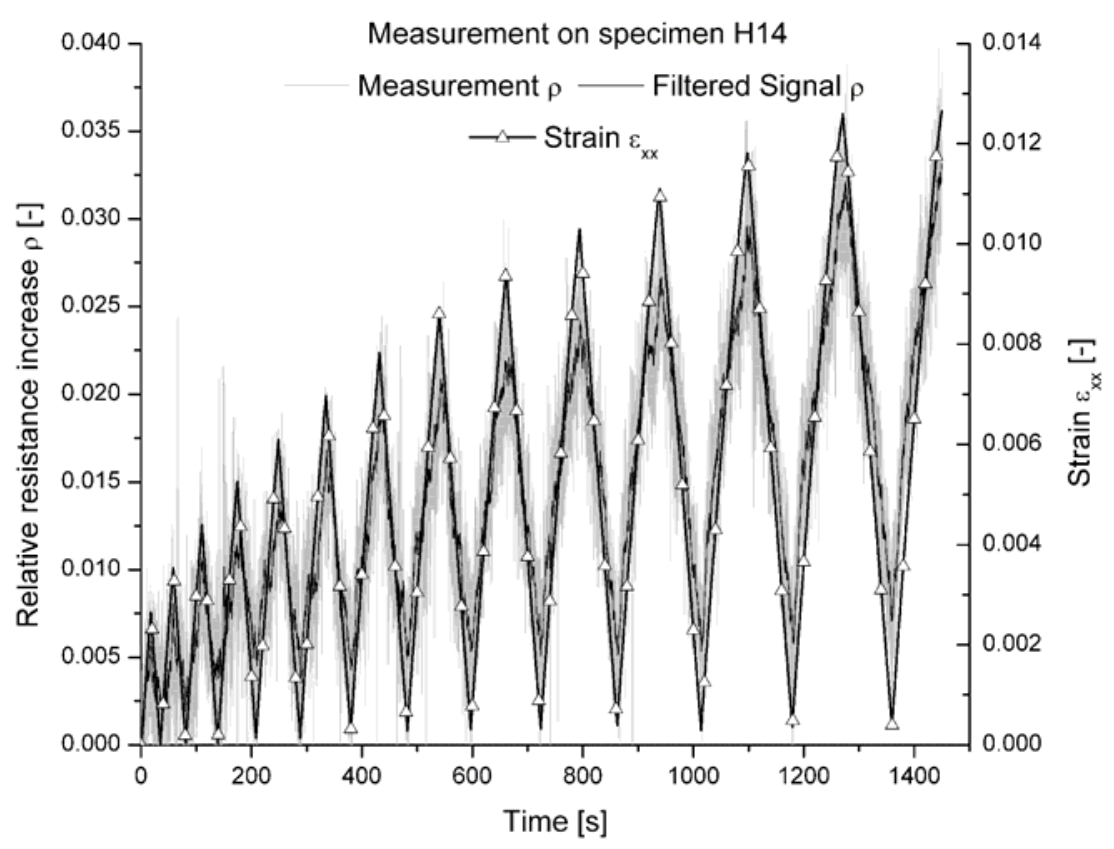

Figure 14 Relative resistance and strain as a function of time for specimen H14.

It was noticed from all the tests that the relative resistance change follows the evolution of the strain as it is supposed to, meaning the rivets and copper conductive tape establish a good constant contact $[5,10]$. During the higher loading cycles, it can be seen that the relative resistance no longer returns to zero, which means that this method is sensitive to the occurring damage. 


\subsection{Fatigue tests}

Because of the good results from the hysteresis tests, considering the fact that the material under study is a fabric-reinforced instead of a unidirectional reinforced, the method is now used for monitoring fatigue tests. Two types of tests were performed; the first has a loading frequency of $2 \mathrm{~Hz}$ and the second of $5 \mathrm{~Hz}$. Two frequencies were chosen to assess whether the frequency has an influence on the evolution of elastic and fatigue parameters and to see whether the resistance measurement still follows the loading at higher frequencies. Both tests were done between $\sigma_{\min }=0$ and $\sigma_{\max }=550 \mathrm{MPa}(\mathrm{R}=0)$. The latter is about $75 \%$ of the ultimate stress (Table 2$)$ which should be high enough for damage to occur. Preliminary tests yielded infinite lifetime at stresses below $450 \mathrm{MPa}$ and for stresses higher than $600 \mathrm{MPa}$, failure occurred after no more than a few hundred cycles.

Figure 15 and Figure 16 show the evolution of the relative resistance change as a function of time for a few fatigue cycles, as well as the corresponding strain for the test at respectively 2 and $5 \mathrm{~Hz}$. It can be noted that $\rho$ clearly follows the loading and unloading of the specimen in both cases.

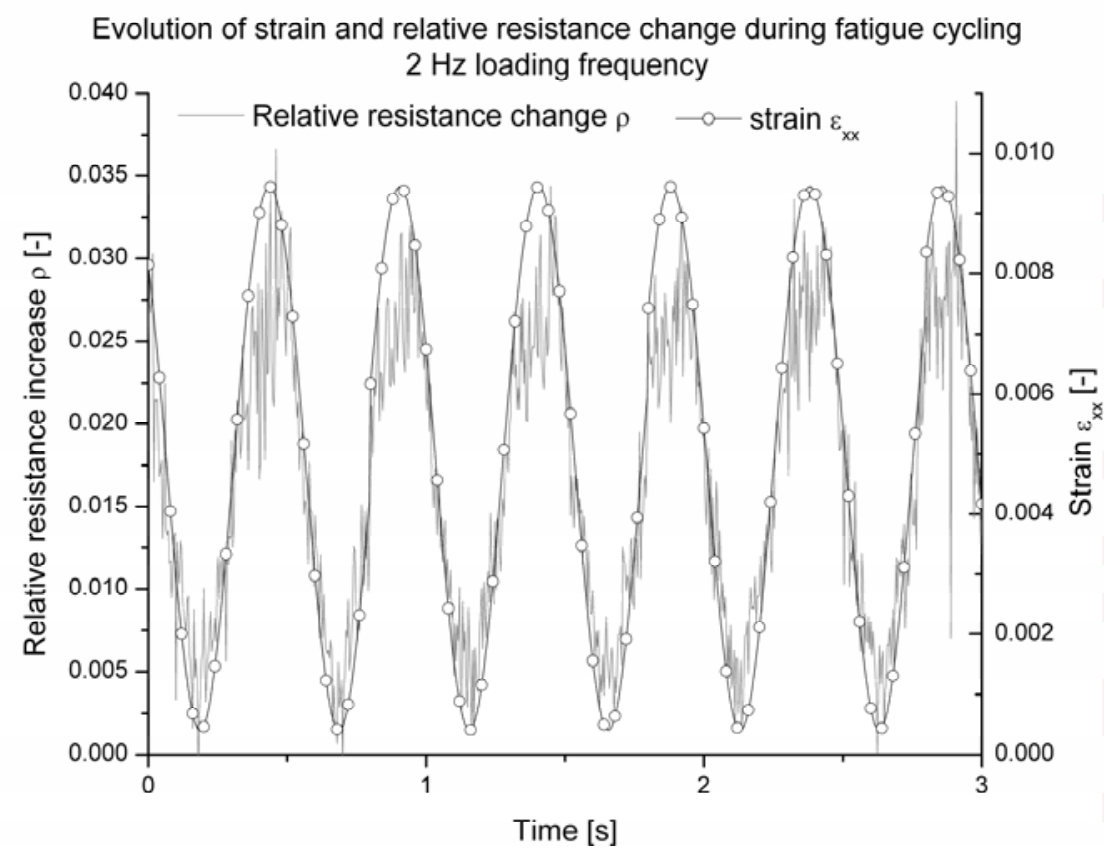

Figure 15 Strain and resistance change during fatigue cycling at $2 \mathrm{~Hz}$, specimen $\mathrm{K} 4$. 


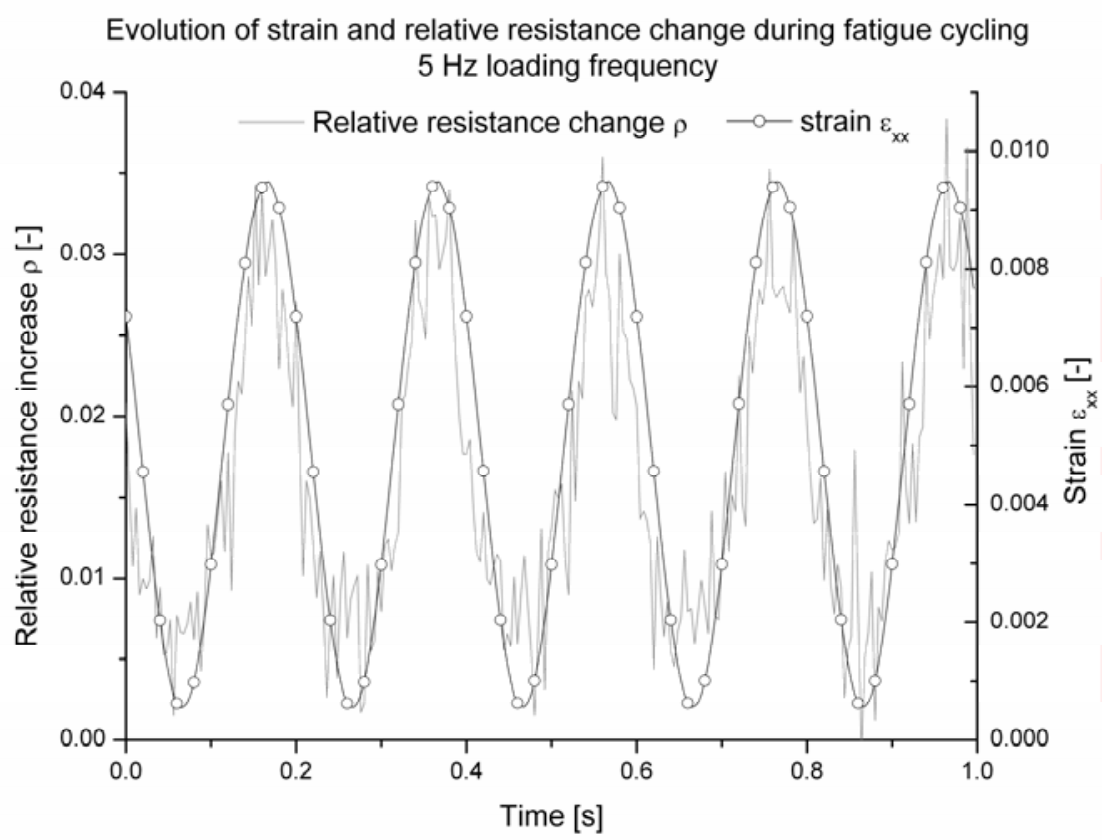

Figure 16 Strain and resistance change during fatigue cycling at $5 \mathrm{~Hz}$, specimen M1.

During the fatigue test, every five minutes five cycles are registered by the dataacquisition system and the maximum, minimum and mean value of these measurements (load, displacement, strain and resistance) are calculated. Figure 17 shows the evolution of these values for the longitudinal strain for both a $2 \mathrm{~Hz}$ and a $5 \mathrm{~Hz}$ test until failure of the specimen. It can be seen that for the two tests, the strain behaviour is much alike. Furthermore, only a very limited increase is registered of about 1E-10 per cycle.

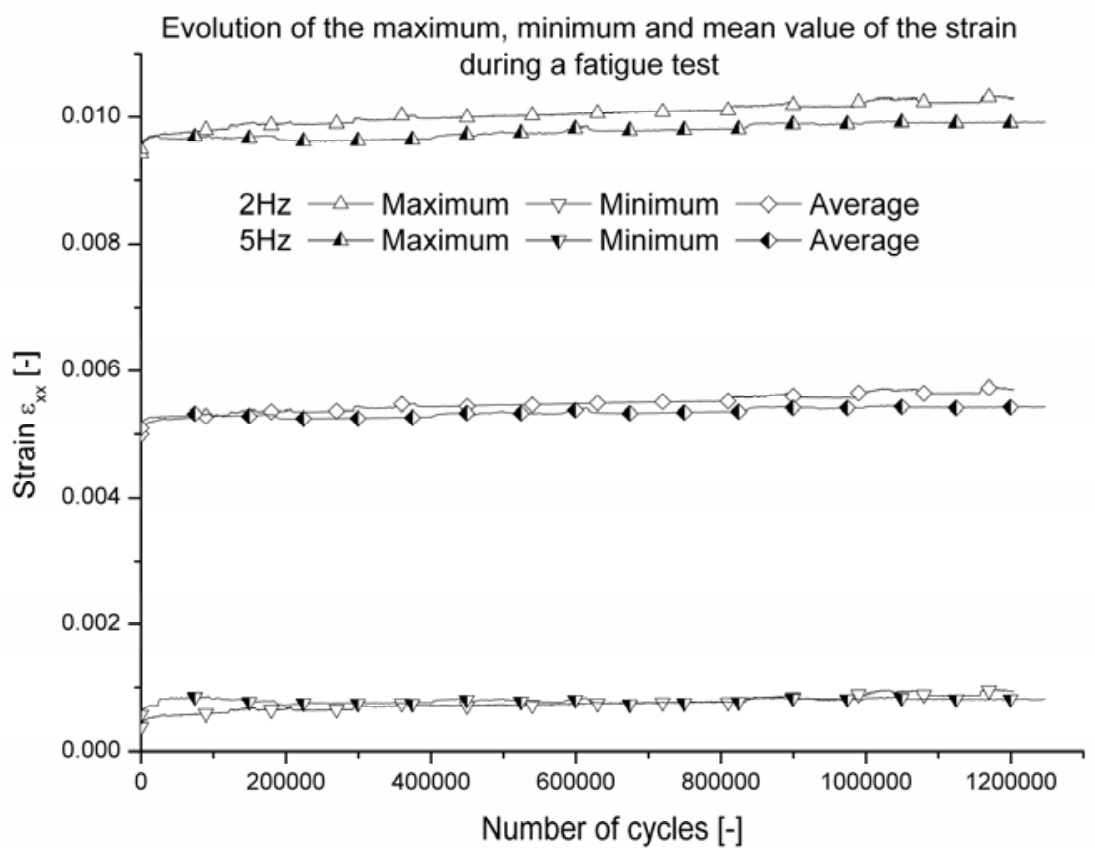

Figure 17 Illustration of the evolution of the maximum, minimum and mean value of the strain as a function of the number of fatigue cycles for both a $2 \mathrm{~Hz}$ and a $5 \mathrm{~Hz}$ test.

One can also notice that the amplitude of the strain (= difference between the maximum and minimum value) does not significantly increase. Since the tests were done in load- 
controlled manner, the stress amplitude is constant, meaning that no real stiffness degradation occurs. As a result, the damage growth cannot be monitored by stiffness degradation or by permanent elongation. The latter is typical for the material under study, there are no off-axis plies, only the warp and weft direction is used for the stacking sequence $\left[\left(0^{\circ}, 90^{\circ}\right)\right]_{4 s}$. Furthermore, this material exhibits very brittle fracture behaviour; failure occurs quite sudden, without any preliminary (visible or audible) cracks.

To assess whether damage can be visualised by the relative resistance change, the evolution of its average value during cycling is plotted in Figure 18 for the $2 \mathrm{~Hz}$ test. The corresponding temperature is also added, to evaluate whether there is a temperature increase due to the used $1000 \mathrm{~mA}$ and whether the temperature increases near the end of life of the specimen. It should be noted that the temperature remains constant throughout the test.

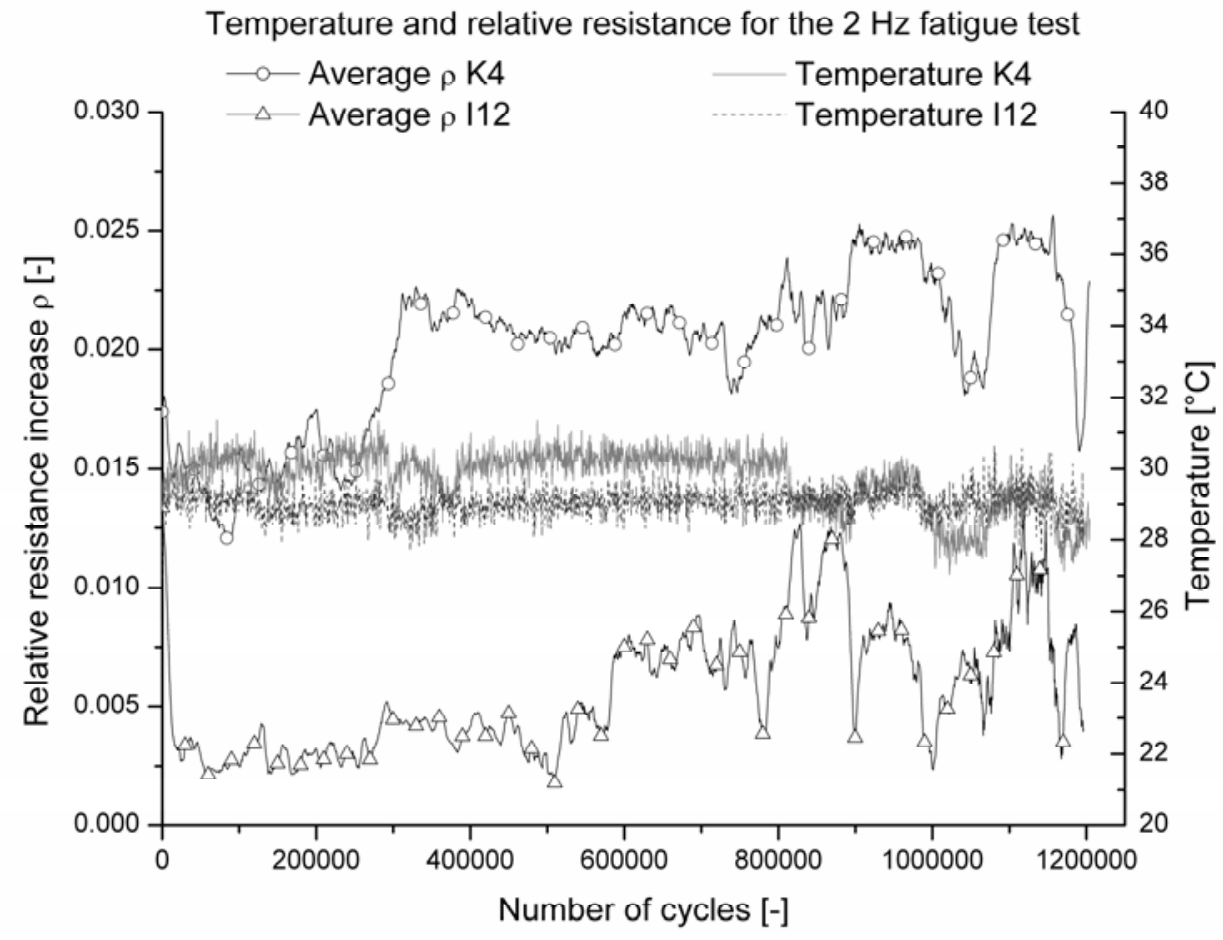

Figure 18 Evolution of the relative resistance change and the temperature throughout the $2 \mathrm{~Hz}$ fatigue test.

One would expect that the resistance curves for both tests would be coincident, since the relative resistance is plotted instead of the absolute value, but this is not the case. The two specimens were sawn from different plates and maybe this causes the difference in measurements. However, it can be noted that both curves have a similar increase of 6.989E-09 per cycle for K4 and 5.185E-09 per cycle for I12 (the given values are the slopes of fitted linear trend lines). These values, however, are not much higher than the increase in strain, which is of the order 1E-10 per cycle. As such, the evolution of the resistance is no great improvement for monitoring damage. This could be explained by the fact that the longitudinal resistance that is being measured is highly influenced by failure of the carbon fibres. Since there is neither real stiffness degradation nor permanent elongation that suggests fibre damage and a very sudden brittle failure, the expected increase of resistance of the specimen is limited. This could also be concluded from the damage model in [4] where a correlation was found between stiffness 
degradation and the reverse of the relative resistance increase. Since the material used in [4] exhibited a large decrease in stiffness, a large increase (up to 0.3) in relative resistance was measured.

In some cases however, a decrease in resistance is noticed instead of an increase. An example of such a test is shown in Figure 19, where the average value of the relative resistance change is depicted. First, there is a significant increase in relative resistance, but than it gradually decreases. Failure occurred after 347757 cycles. This phenomenon of a decreasing resistance has already been reported in literature $[12,13]$ and is due to an increase in the degree of fibre alignment and due to a reduction of residual stress [13]. However, this usually only happens during the first few hundred cycles of the fatigue test. In this case, the decrease may be explained by an increasing number of adjacent fibres that make contact, due to matrix damage.

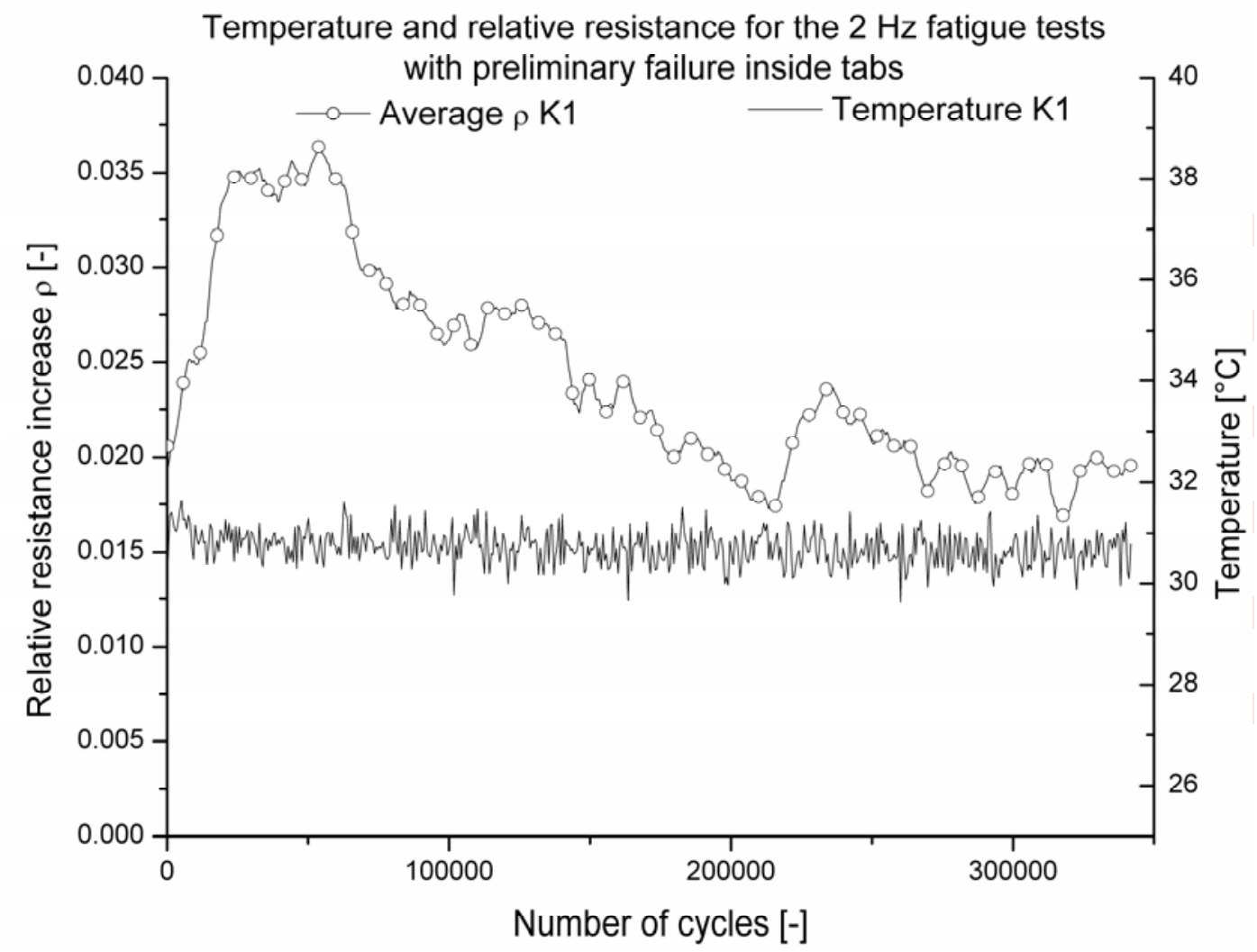

Figure 19 Evolution of the relative resistance change and the temperature throughout a $2 \mathrm{~Hz}$ fatigue test with a decreasing resistance.

For the $5 \mathrm{~Hz}$ test, the problem of tab failure occurred more often. A lot of test samples failed during the first 50000 cycles due to stress concentration in the tabs [20] or gradual decay of the adhesive resulting in heating due to friction between tabs and specimen with failure as result. Since the purpose of the resistance measurement is to predict damage and failure, two of these experiments are shown in Figure 20. It can be noted that there is no significant increase in temperature. The relative resistance increases about $1.378 \mathrm{E}-07$ per cycle, which still is not suited for damage monitoring, although it is almost 100 times higher than for the $2 \mathrm{~Hz}$ samples. Furthermore, there is no significant change in evolution right before failure, so failure predictability does not seem possible. 
It should be noted that there is a small decrease for M1 and a large decrease for M2 in resistance for the first 2000 cycles, which may be due to the increase in the degree of fibre alignment and due to a reduction of residual stress [13], as previously mentioned.

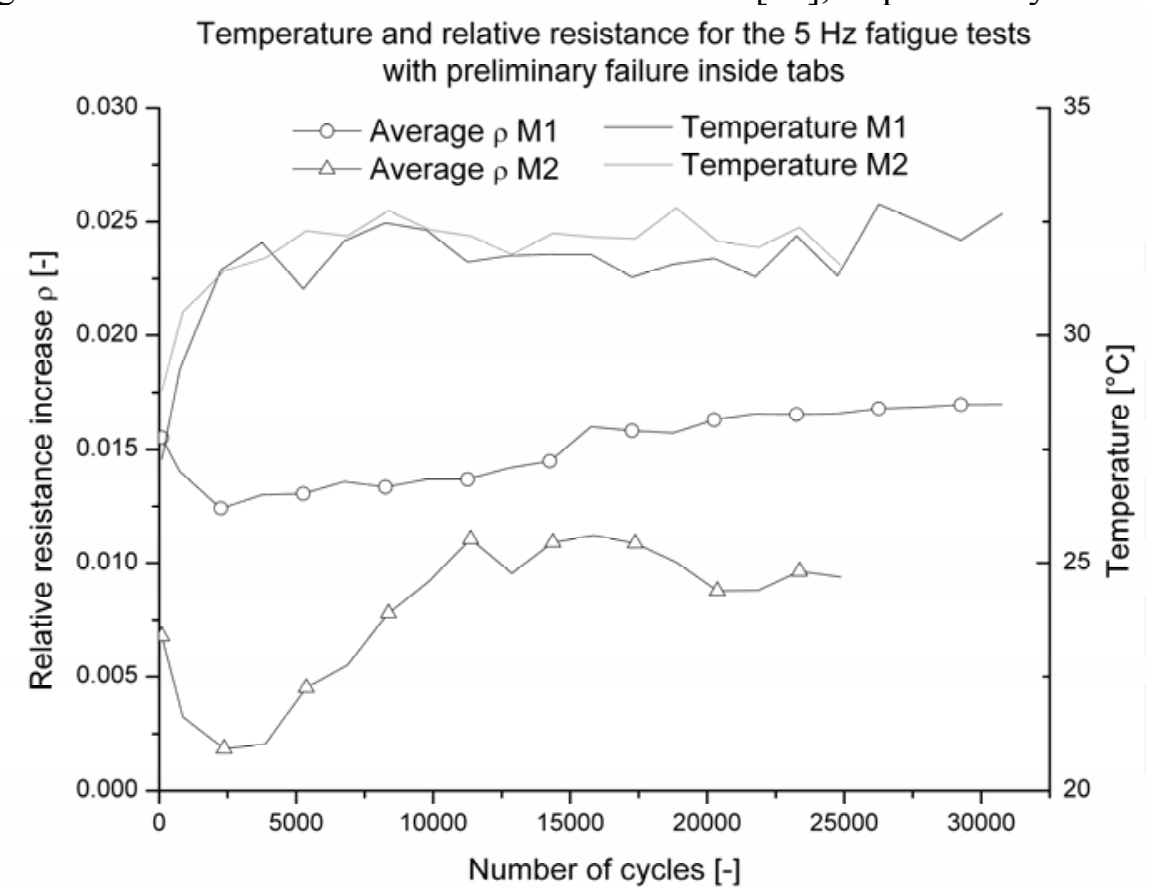

Figure 20 Evolution of the relative resistance change and the temperature throughout the $5 \mathrm{~Hz}$ fatigue test for the specimens with preliminary failure.

An example of a successful test at $5 \mathrm{~Hz}$ is shown in Figure 21. Again, the temperature remains constant until failure of the specimen at 1296769 cycles. It must be noted that in this case, again, the relative resistance tends to decrease, as was the case with the $2 \mathrm{~Hz}$ test in Figure 19, so this phenomenon does not depend on the used frequency. Again, this evolution of the relative resistance cannot be used to monitor damage or predict failure. 
Temperature and relative resistance for the $5 \mathrm{~Hz}$ fatigue test

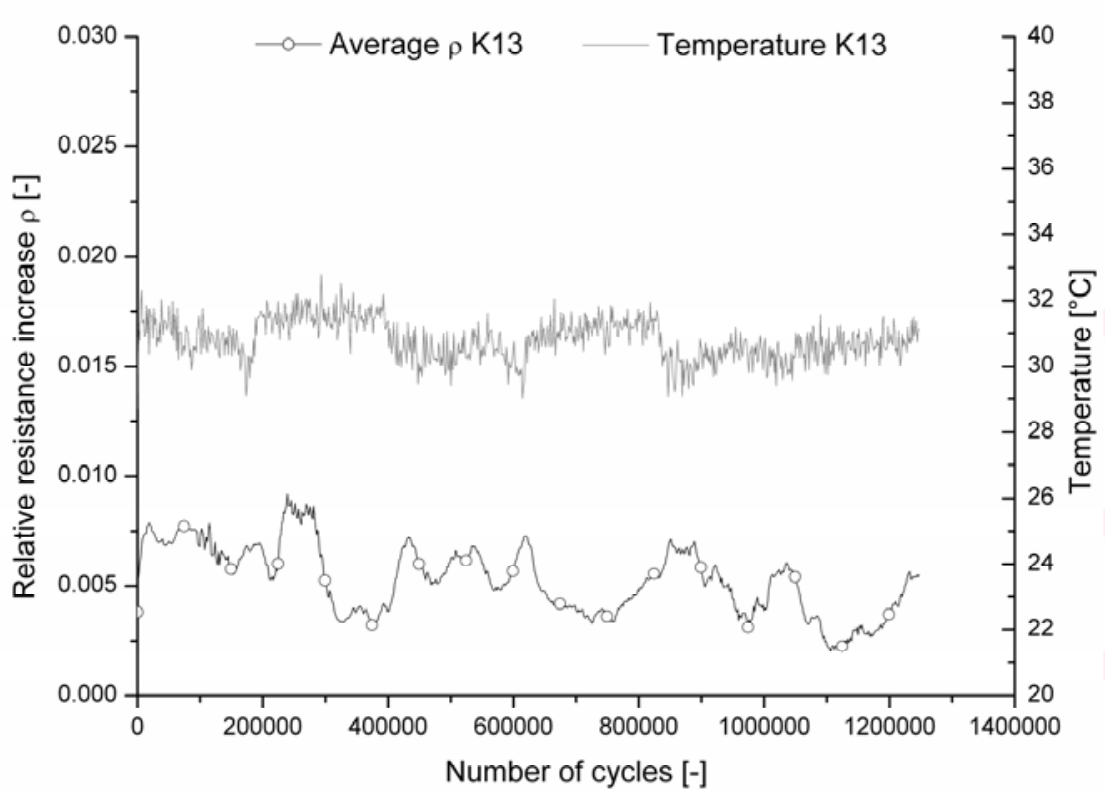

Figure 21 Evolution of the relative resistance change and the temperature throughout the $5 \mathrm{~Hz}$ fatigue test.

\section{Conclusions}

This study investigates the use of electrical resistance measurement on carbon fabric reinforced Polyphenylene Sulphide (PPS) for monitoring fatigue damage. Two rivets, placed in a strain free zone outside the tabbed section, were used to inject the current in the specimen, but a two-probe method was not stable for an extended period of time and therefore, a four-probe method was presented. The sensitivity of this four-probe method for the material under study is more than twice as high when compared to the two-probe method, as was proven by quasi-static tests. Then, several hysteresis tests were performed, which provided proof that the resistance follows the load and a small increase resulting from damage is present.

Finally, several fatigue tests were done to assess the performance of the resistance measurement in damage detection. Two frequencies, 2 and $5 \mathrm{~Hz}$, were chosen to assess the influence of the frequency on the fatigue lifetime and damage growth. It could be concluded that the frequency does not have any demonstrable influence; in both cases, no stiffness degradation occurred and only a limited amount of permanent deformation was present. Furthermore, this material exhibits very brittle fracture behaviour; failure occurs quite sudden, without any preliminary (visible or audible) cracks.

As a result, the electrical resistance measurement could not monitor damage growth, since no measurable damage was present. The longitudinal resistance is very sensitive to fibre failure and since neither stiffness-reduction nor permanent elongation occurred, the dominant damage mode is not a gradual increase in the number of fibres that break under fatigue loading conditions.

\section{Acknowledgements}

The authors are highly indebted to the university research fund BOF (Bijzonder Onderzoeksfonds UGent) for sponsoring this research and to Ten Cate Advanced Composites for supplying the material. 


\section{References}

[1] Schulte, K. and Baron, Ch. Load and failure analysis of CFRP laminates by means of electrical resistivity measurements. COMPOSITES SCIENCE AND TECHNOLOGY 36, 63-76,1989

[2] Kupke M, Schulte K and Schuler R. Non-destructive testing of FRP by d.c. and a.c. electrical methods. COMPOSITES SCIENCE AND TECHNOLOGY 61 (6): 837-847 2001.

[3] Abry JC, Choi YK, Chateauminois A, Dalloz B, Giraud G, Salvia M, In-situ monitoring of damage in CFRP laminates by means of AC and DC measurements, COMPOSITES SCIENCE AND TECHNOLOGY 61 (6): 855-864, 2001

[4] Seo DC, Lee JJ, Damage detection of CFRP laminates using electrical resistance measurement and neural network, COMPOSITE STRUCTURES 47 (1-4): 525-530 DEC, 1999

[5] Angelidis N, Wei CY, Irving PE , The electrical resistance response of continuous carbon fibre composite laminates to mechanical strain, COMPOSITES PART A-APPLIED SCIENCE AND MANUFACTURING 35 (10): 1135-1147, 2004

[6] Park JB, Okabe T, Takeda N, Curtin WA, Electromechanical modelling of unidirectional CFRP composites under tensile loading condition, COMPOSITES PART A-APPLIED SCIENCE AND MANUFACTURING 33 (2): 267-275, 2002

[7] Park JB, Okabe T, Takeda N, New concept for modeling the electromechanical behavior of unidirectional carbon-fiber-reinforced plastic under tensile loading, SMART MATERIALS \& STRUCTURES 12 (1): 105-114 FEB, 2003

[8] Xia Z, Okabe T, Park JB, Curtin WA, Takeda N, Quantitative damage detection in CFRP composites: coupled mechanical and electrical models, COMPOSITES SCIENCE AND TECHNOLOGY 63 (10): 1411-1422 AUG, 2003

[9] Abry JC, Bochard S, Chateauminois A, Salvia M, Giraud G, In situ detection of damage in CFRP laminates by electrical resistance measurements, COMPOSITES SCIENCE AND TECHNOLOGY 59 (6): 925-935, 1999

[10] Todoroki A, Yoshida J, Electrical resistance change of unidirectional CFRP due to applied load, JSME INTERNATIONAL JOURNAL SERIES A-SOLID MECHANICS AND MATERIAL ENGINEERING 47 (3): 357-364, JUL 2004

[11] Irving PE, Thiagarajan C, Fatigue damage characterization in carbon fibre composite materials using an electrical potential technique, SMART MATERIALS \& STRUCTURES 7 (4): 456466 AUG, 1998

[12] Wang XJ, Chung DDL, Self-monitoring of fatigue damage and dynamic strain in carbon fiber polymer-matrix composite, COMPOSITES PART B-ENGINEERING 29 (1): 63-73,1998

[13] Wang XJ, Chung DDL, Real-time monitoring of fatigue damage and dynamic strain in carbon fiber polymer-matrix composite by electrical resistance measurement, SMART MATERIALS \& STRUCTURES 6 (4): 504-508, AUG 1997

[14] Weber I. and Schwartz P. Monitoring bending fatigue in carbon-fibre/epoxy composite strands: a comparison between mechanical and resistance techniques. COMPOSITES SCIENCE AND TECHNOLOGY 61 (6): 849-853 2001

[15] I. De Baere, W. Van Paepegem and J. Degrieck, The use of rivets for electrical resistance measurement on carbon fibre-reinforced thermoplastics, Smart Materials and Structures 16 (2007) 1821-1828.

[16] I. De Baere, W. Van Paepegem, J. Degrieck, H. Sol , D. Van Hemelrijck and A. Petreli, Comparison of different identification techniques for measurement of quasi-zero Poisson's ratio of fabric reinforced laminates. Composites A 38 (9) pp. 2047-2054.

[17] Todoroki A, Omagari, K, Shimamura Y, and Kobayashi H, Matrix crack detection of CFRP using electrical resistance change with integrated surface probes, Composites Science and Technology, Volume 66, Issues 11-12, September 2006, Pages 1539-1545

[18] J. B. Park, T. K. Hwang, H. G. Kim and Y. D. Doh, Experimental and numerical study of the 
electrical anisotropy in unidirectional carbon-fiber-reinforced polymer composites, Smart Materials and Structures Volume 16 February 2007 pages 57-66.

[19] D.D.L. Chung, Shoukai Wang, Discussion on paper "The electrical resistance response of continuous carbon fibre composite laminates to mechanical strain" by N. Angelidis, C.Y. Wei and P.E. Irving, Composites: Part A 35, 1135-1147 (2004), Composites Part A: Applied Science and Manufacturing, Volume 37, Issue 9, pages 1490-1494 .

[20] I. De Baere, W. Van Paepegem and J. Degrieck. On the design of end tabs for quasi-static and fatigue testing of fibre-reinforced composites. ACCEPTED for Polymer Composites. 